\title{
EFEITO DE REGIMES ALIMENTARES SOBRE O PESO CORPO- RAL E PARÂMETROS REPRODUTIVOS DE CABRAS NATIVAS
}

\author{
EFFECT OF ALIMENTARY REGIMES ONBODY WEIGHT \\ AND REPRODUCTIVE PARAMETERS OF NATIVE GOATS
}

\author{
Nogueira, D.M. ${ }^{\text {* }}$, Voltolini, T.V. ${ }^{1}$, Moreira, J.N. ${ }^{1}$, Lopes Júnior, E.S. ${ }^{2}$ e Oliveira, V.G. de ${ }^{3}$ \\ ${ }^{1}$ Pesquisador da Embrapa Semiárido. Petrolina-PE. Brasil. *daniel.nogueira@cpatsa.embrapa.br \\ ${ }^{2}$ Universidade Federal do Vale do São Francisco-UNIVASF. Petrolina-PE. Brasil. \\ ${ }^{3}$ Universidade Federal Rural de Pernambuco-UFRPE. Recife-PE. Brasil.
}

\section{PALAVRAS CHAVE ADICIONAIS}

Ciclo estral. Fertilidade.

\section{RESUMO}

Objetivou-se com esse trabalho avaliar o efeito de diferentes regimes alimentares sobre o consumo de matéria seca, variação do peso corporal e os parâmetros reprodutivos de cabras exploradas na região semiárida do Nordeste do Brasil. Foram utilizadas 56 cabras distribuídas homogeneamente em quatro tratamentos: dieta 1) caatinga e palma forrageira; dieta 2) caatinga, palma forrageira e concentrado; dieta 3) capim-buffel e palma forrageira; dieta 4) capim-buffel, palma forrageira e concentrado. Foram observados maiores $(p<0,05)$ ganhos de pesos totais e ganhos médios diários nas cabras que pastejaram capimbuffel ou caatinga recebendo suplementação com palma e concentrado. Os regimes alimentares utilizados possibilitaram ganhos de peso de até 16 g/animal/dia durante o período seco. O desempenho reprodutivo das cabras não foi influenciado $(p>0,05)$ pelos regimes alimentares. Conclui-se que a suplementação com palma e concentrado melhorou o ganho de peso das cabras, no entanto, não influenciou na atividade estral, taxa de parição ou prolificidade dessas fêmeas.

\section{SUMMARY}

This work aimed to evaluate the effect of different alimentary regimes on the dry matter intake, corporal weight variation and reproductive parameters of goats raised in the semi-arid region of Northeastern Brazil. Fifty-six goats were distributed into four treatments: diet 1) caatinga

Recibido: 29-6-10. Aceptado: 8-11-10.

\author{
AdDitionAL KEYWORDS \\ Estral cycle. Fertility.
}

and palm forage; diet 2) caatinga, palm forage and concentrate; diet 3 ) buffel grass and palm forage; diet 4) buffel grass, palm forage and concentrate. It was observed greater $(p<0.05)$ total weight gain and daily weight gain in the goats which were under buffel grass pasture or caatinga receiving supplementation with palm forage and concentrate. The alimentary regimes promoted the weight gain up to $16 \mathrm{~g} / \mathrm{animal} /$ day during the dry season. The reproductive performance was not influenced ( $p>0.05$ ) by the alimentary regimes. In conclusion, diets receiving supplementation with palm forage and concentrate increased the goat's weight gain; however, it did not affect the estrus behavior, parturition rate or prolificity of these females.

\section{INTRODUÇÃO}

A exploração de caprinos na região Nordeste do Brasil é caracterizada por baixos níveis de produtividade. Nesta região, as fêmeas caprinas, em geral, apresentam estro em todos os meses do ano, sendo consideradas poliéstricas contínuas (Simplício et al., 1986). No entanto, segundo os mesmos autores, em regime de exploração extensivo, as fêmeas, quando mantidas em pastagem nativa da caatinga, apresentam no período chuvoso maior atividade sexual. Em caprinos e ovinos, a súbita disponibilidade de boa nutrição e ingestão de níveis crescentes 
de energia pode induzir o estro e a ovulação (Martin et al., 2004; Zarazaga et al., 2005).

Na região submédio do São Francisco, ao longo do período seco, que normalmente se distribui de julho a dezembro, são observadas perdas substanciais na disponibilidade e na qualidade de forragem da caatinga, com reflexos sobre a produtividade dos rebanhos. Portanto, durante o período seco, o uso de pastagens de capim-buffel de forma exclusiva pode não atender as exigências nutricionais dos animais. Nesse caso, a suplementação com palma forrageira e concentrado pode ser uma alternativa importante, a fim de proporcionar uma melhora no desempenho dos animais.

Para o semiárido brasileiro, há uma carência de informações que avaliem o efeito de regimes alimentares, que empregaram a vegetação da caatinga, o capim-buffel, a palma forrageira ou suplementos concentrados sobre o desempenho produtivo e reprodutivo de caprinos. Objetivou-se com esse trabalho avaliar o efeito de diferentes regimes alimentares sobre a variação de peso corporal e os parâmetros reprodutivos de cabras nativas exploradas no Nordeste do Brasil.

\section{MATERIALE MÉTODOS}

O experimento foi conduzido em 2008 no campo experimental da Embrapa Semiárido em Petrolina, Submédio do São Francisco, localizado a $09^{\circ} 09^{\prime} \mathrm{Sul}$ e $40^{\circ} 22^{\prime}$ Oeste e precipitação média anual de $520 \mathrm{~mm}$ (Embrapa Semiárido, 2010).

Através de controle zootécnico do rebanho, foram utilizadas 56 cabras sem padrão racial definido ou nativas da raça Canindé, sendo, cíclicas, multíparas e não lactantes. As fêmeas apresentaram, ao início do experimento, uma média de idade de 2,6 $\pm 1,4$ anos e escore de condição corporal de $2,7 \pm 0,4$ (escala de 1 a 5).

As fêmeas foram distribuídas homogeneamente em 4 regimes alimentares: Dieta 1 $(n=14)$, vegetação da caatinga associada a suplementação com palma forrageira; Dieta $2(n=14)$, caatinga, palma e concentrado; Dieta $3(n=14)$, pastagem de capim-buffel (Cenchrus ciliaris) associado à palma e Dieta $4(n=14)$, capim-buffel com palma e concentrado. O concentrado foi fornecido na quantidade de $200 \mathrm{~g}$ /animal, uma vez ao dia, sendo composto por farelo de soja, farelo de trigo e milho grão moído, contendo $73 \%$ de nutrientes digestíveis totais (NDT) e $18 \%$ de proteína bruta. A palma forrageira foi colhida diariamente, cortada e oferecida na quantidade média de 3,50 kg/animal/dia. Água e suplemento mineral foram fornecidos à vontade. As cabras permaneceram na pastagem de capim-buffel ou vegetação da caatinga das 7:00 às 15:00 horas e, posteriormente, foram recolhidas e distribuídas em quatro baias, de acordo com o regime alimentar. As pesagens dos animais foram realizadas a cada 28 dias após jejum de sólidos por 16 horas. Durante o período de julho a dezembro, com o auxílio de dois machos vasectomizados (rufiões), as cabras foram observadas quanto à ocorrência de estro, duas vezes ao dia, por 30 a 60 minutos, e a duração do ciclo estral, classificado, em normal (16 a 27 dias), curto ( $<16$ dias) e longo ( $>27$ dias).

No início do período chuvoso, em dezembro, foi realizada a monta controlada das cabras, com reprodutores da raça Canindé, Anglo-nubiana e Boer, distribuídos equitativamente nos grupos de fêmeas submetidas aos diferentes regimes alimentares.

O delineamento experimental foi inteiramente casualizado com 4 tratamentos e 14 repetições. Foi verificado o efeito da pastagem, da suplementação e as interações (pastagem x suplementação). As porcentagens de animais em estro, ciclos estrais e as taxas de parição foram comparadas pelo teste do Qui-quadrado. A variação do peso corporal, do número total de estros e a prolificidade foram analisados pelo procedimento ANOVA e as comparações entre médias feitas pelo teste de Tukey, com nível de significância de 5\%. 


\section{REGIMES ALIMENTARES EPARÂMETROS REPRODUTIVOS}

\section{RESULTADOSEDISCUSSÃO}

Apesar de não haver diferença significativa para o consumo de matéria seca, foi observado que as cabras mantidas em pastagens de capim-buffel ou de caatinga suplementadas com palma forrageira em associação com concentrado apresentaram maiores $(p<0,05)$ ganhos de peso totais e ganhos médios diários em relação àquelas que receberam apenas palma forrageira (tabela I). A suplementação com concentrado mostrou-se adequada para a manutenção dos pesos corporais, bem como, ganhos de peso moderados $(9,7 \mathrm{~g} /$ dia a $16,2 \mathrm{~g} / \mathrm{dia})$ durante a época seca do ano para cabras de corte. Aganda et al. (2001) trabalharam com caprinos jovens, alimentados com $40 \%$ de capim-buffel e $60 \%$ de alfafa, e observaram ganhos médios de 43,0 g/dia.

Não houve interação entre o pasto (capim-buffel ou caatinga) e as suplementações $(p>0,05)$. As perdas de peso observadas nas cabras suplementadas somente com palma forrageira podem ser explicadas pelo baixo valor nutritivo das pastagens de caatinga e de capim-buffel ao longo dos meses da estação seca, que contribuíram para a redução na quantidade e qualidade da forragem, promovendo a redução no peso corporal dos animais.

Os regimes alimentares não afetaram ( $p>0,05)$ o comportamento estral das cabras (tabela I). Os maiores ganhos de peso com o uso de suplemento concentrado não foram suficientes para promover o maior número total de estros nem de ciclos estrais. Diferentemente dos dados desse estudo, Zarazaga et al. (2005) observaram que a dieta com maior nível de energia e proteína promoveu aumento da atividade estral e a redução do período de anestro estacional. Os mesmos autores observaram uma maior incidência de ciclos normais $(67,8 \%)$ e menor de ciclos curtos $(9,4 \%)$ e ciclos longos $(22,8 \%)$.

Das 56 cabras expostas à monta controlada, 41 cabras $(73,2 \%)$ foram observadas em estro e cobertas pelos reprodutores. Deste total, 33 cabras $(80,5 \%)$ pariram e apresentaram uma prolificidade média de 1,4 crias. Não foi observada diferença significativa $(p>0,05)$ para a porcentagem de cabras cobertas, paridas nem para prolificidade

Tabela I. Consumo de matéria seca, variação de peso corporal e parâmetros reprodutivos de cabras recebendo diferentes regimes alimentares. (Dry matter intake, body weight variation and reproductive parameters of goats kept under different alimentary regimes).

\begin{tabular}{lccccc}
\hline \multirow{2}{*}{ Parâmetros } & \multicolumn{2}{c}{ Caatinga +} & \multicolumn{2}{c}{ Capim-buffel + } \\
& Palma & Concentrado & Palma & Concentrado & EPM $^{*}$ \\
\hline Consumo de matéria seca $(\mathrm{kg})^{*}$ & 0,380 & 0,596 & 0,322 & 0,494 & - \\
Peso corporal inicial $(\mathrm{kg})$ & 32,60 & 31,70 & 32,16 & 32,40 & 1,54 \\
Ganho de peso total (kg/168 dias) & $-1,71^{\mathrm{b}}$ & $1,63^{\mathrm{a}}$ & $-0,87^{\mathrm{b}}$ & $2,73^{\mathrm{a}}$ & 0,72 \\
Ganho médio diário (g/dia) & $-10,20^{\mathrm{b}}$ & $9,70^{\mathrm{a}}$ & $-5,20^{\mathrm{b}}$ & $16,24^{\mathrm{a}}$ & 4,32 \\
Estros totais, n & 33 & 33 & 48 & 40 & - \\
Ciclos normais, n (\%) & $6(28,6)$ & $4(19,0)$ & $10(30,3)$ & $7(26,9)$ & - \\
Ciclos curtos, n (\%) & $5(23,8)$ & $3(14,3)$ & $7(21,2)$ & $7(26,9)$ & - \\
Ciclos longos, n (\%) & $10(47,6)$ & $14(66,7)$ & $16(48,5)$ & $12(46,2)$ & - \\
Taxa de parição, n (\%) & $9 / 10(90,0)$ & $7 / 8(87,5)$ & $9 / 13(69,2)$ & $8 / 10(80,0)$ & - \\
Prolificidade, n & 1,3 & 1,6 & 1,4 & 1,6 & 0,24 \\
\hline
\end{tabular}

*Matéria seca da palma ou palma + concentrado. EPM: Erro padrão da média.

ab Valores com letras sobrescritas diferentes na mesma linha diferem estatisticamente $(p<0,05)$. 


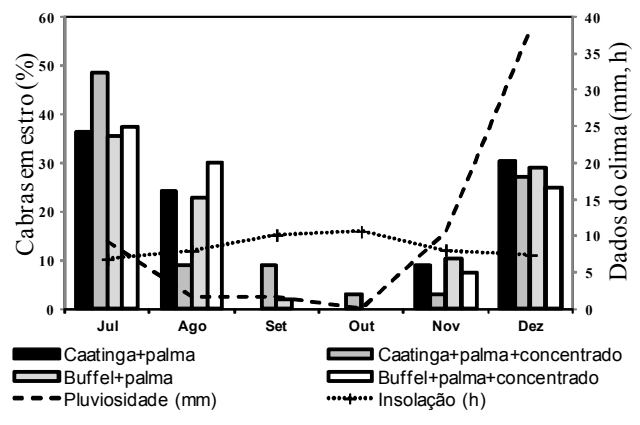

* Set e Out houve menor incidência de estros $(p<0,05)$.

Figura 1. Porcentagem de cabras em estro e dados de pluviosidade e insolação durante o período de julho a dezembro de 2008. (Percentage of goats showing estrus, and rainfall and sun's light data from June to December, 2008).

entre os diferentes regimes alimentares (tabela I). Zarazaga et al. (2005) também não observaram o efeito de planos alimentares sobre a taxa de ovulação e, consequentemente, da prolificidade. Segundo Martin et al. (2004), durante a estação reprodutiva, o incremento do nível nutricional pode influenciar, positivamente, a proporção de cabras ovulando e a prolificidade.

Foi observada uma maior incidência de ciclos estrais longos em todas as dietas (tabela I). Este fato pode ser explicado pela pouca manifestação de estros nos meses

\section{BIBLIOGRAFIA}

Aganga, A.A., Omphile, U.J. and Baleseng, L. 2001. Performance of Tswana goats fed with Acacia mellifera, Euclea undulate and Peltophorum africanum as a supplement to Buffel grass. Arch. Zootec., 50: 383-386.

Embrapa Semárido. 2010. http://www.cpatsa. embrapa.br (05/06/2010).

Martin, G.M., Rodger, J. and Blache, D. 2004. Nutritional and environmental effects on reproduction in small ruminant. Reprod. Fert. Develop., 16: 491-501. setembro e outubro, período seco do ano (figura 1). Ou seja, foi observada a ocorrência de maiores $(p<0,05)$ concentrações de estros no mês de julho e início de agosto, após a introdução dos rufiões, como consequência do efeito macho (Martin et al., 2004), e entre o final de novembro a dezembro, após as primeiras chuvas.

As primeiras chuvas foram registradas em novembro e dezembro, perfazendo um total de $50 \mathrm{~mm}$, caracterizando o início do período chuvoso (figura 1). Portanto, a concentração de estros observada nesses meses pode estar relacionada com o início da precipitação pluviométrica e, conseqüentemente, redução da insolação e, possivelmente, maior oferta qualitativa e quantitativa de forragem. Foi observado o efeito da pluviosidade no aparecimento do estro em cabras, onde o comportamento estral é desencadeado em poucos dias, logo após o início das chuvas (Simplício et al., 1986).

\section{CONCLUSÕES}

Independente da pastagem utilizada (caatinga ou capim-buffel), a suplementação com palma e concentrado melhorou o ganho de peso das cabras, no entanto, não influenciou na atividade estral, taxa de parição ou prolificidade dessas fêmeas durante o período seco do ano.

Simplício, A.A., Riera, G.S., Nunes, J.F. and Foote, W.C. 1986. Frequency and duration of estrous cycle and period in genetically non-descript (SRD) type of goats in the tropical Northeast of Brazil. Pesqui. Agropecu. Bras., 21: 535540.

Zarazaga, L.A., Guzmán, J.L., Domínguez, C., Pérez, M.C. and Prieto, R. 2005. Effect of plane of nutrition on seasonality of reproduction in Spanish Payoya goats. Anim. Reprod. Sci., 87: 253-267. 